\title{
Electrical and mechanical dyssynchrony in patients with right bundle branch block
}

\author{
Alejandro Solodky, MD, and Nili Zafrir, MD, FESC, FASNC ${ }^{a}$ \\ a Department of Cardiology, Rabin Medical Center, Tel Aviv University, Petah Tikva, Israel
}

Received Sep 17, 2018; accepted Sep 18, 2018

doi:10.1007/s12350-018-1460-z

\section{See related article, pp. 621-630}

The prevalence of Right Bundle Branch Block $(\mathrm{RBBB})$ as seen in a routine electrocardiogram is about 3 to $5 \%$ of the general population. Patients with RBBB have specific signs of conduction delay seen on ECG with wide QRS (electrical dyssynchrony). RBBB may be associated with some anatomical heart disease and some with arrhythmias. Although the majority of patients with RBBB on ECG have fairly benign reputation, in some reports, $\mathrm{RBBB}$ is an independent predictor of cardiovascular mortality as well as all-cause mortality. ${ }^{1-3}$ Moreover, the new onset of RBBB predicts a higher rate of coronary artery disease, congestive heart failure, and cardiovascular mortality. When cardiac disease is present, the coexistence of RBBB suggests an advanced disease. ${ }^{1}$ One of the mechanisms for heart failure is that RBBB can cause left ventricular mechanical dyssynchrony (LVMD). The LVMD might be interventricular, intraventricular, or both. Several articles showed some correlation with electrical activation. $^{4-7}$ Still, the relationship between electrical disturbance and LVMD is partly unclear among these patients with RBBB.

However, patients with RBBB may have as well LVMD with or without LV dysfunction. The relevance of LVMD in patients with RBBB and LV dysfunction is in applying those patients for cardiac resynchronization therapy (CRT).

The major indication for CRT is in patients with LBBB with QRS width above $120 \mathrm{msec}$ and LV

\footnotetext{
Reprint requests: Nili Zafrir, MD, FESC, FASNC, Department of Cardiology, Rabin Medical Center, Tel Aviv University, Petah Tikva, Israel; zafrirmd@isdn.net.il

J Nucl Cardiol 2020;27:631-3.

$1071-3581 / \$ 34.00$

Copyright (C) 2018 American Society of Nuclear Cardiology.
}

dysfunction and heart failure. ${ }^{8-10}$ The importance of LVMD in those patients with LBBB has been vastly studied by several imaging modalities especially by echo-Doppler, and also by MRI and phase analysis by GATED SPECT MPI. ${ }^{8-12}$ LVMD in LBBB is part of the guidelines in selection of patients for CRT.

Several studies compared the efficiency of LVMD in LBBB compared to RBBB. The first study on dogs by MJ Byrne et al found that less LVMD is induced by RBBB than in LBBB in failing hearts as such the impact of CRT on these dogs is reduced. ${ }^{8}$

RBBB was studied in patients with impaired LV function. It was found that patients with increased time difference (TD) of septal-lateral activation by echoDoppler, improved clinically after CRT. ${ }^{4}$

However in a large study on 561 consecutive patients who received CRT, $89(16 \%)$ patients had RBBB. LV dyssynchrony was assessed by tissue echoDoppler, before and 6 months after CRT. The authors found that at long-term follow-up, LVMD and mitral regurgitation were identified as independent predictors of all-cause mortality and heart failure hospitalization among RBBB patients. ${ }^{12}$ As such assessment of LVMD may have a crucial decision in the treatment of CHF patients with RBBB by selecting CRT as a preferable treatment in addition to medical therapy.

Most of those studies assessing the LVMD in patients with RBBB were done by echo-Doppler. Although there are many publications on LVMD including different clinical subsets by phase analysis and SPECT MPI, ${ }^{10-17}$ the issue on patients with RBBB specifically has not been evaluated.

In this issue of the Journal of Nuclear Cardiology, Sillanmaki et al. ${ }^{18}$ studied patients with RBBB by vector electrocardiography (VECG) compared to the control group. They investigated LVMD by phase analysis from gated SPECT MPI. Reviewing the literature, it is the first study that investigates LVMD by phase analysis SPECT MPI specifically in patients with RBBB on vector ECG. 
They studied 30 patients with RBBB and 60 matching controls with vector electrocardiography and myocardial perfusion imaging (MPI) phase analysis. RBBB group was divided into those with and those without LVMD measured by phase standard deviation (SD) and histogram bandwidth (BW).

They found that the prevalence of LVMD among RBBB patients was $50 \%$ and among controls $22 \%$. Odds ratio (OR) for LVMD in patients with RBBB vs. controls without RBBB was 3.6 (95\% CI 1.4 to 9.3). Ejection fraction (EF), end-systolic volume, the angle between QRS and T vectors, and the QRS angle in the sagittal plane were significantly different between RBBB patients with and without LVMD. The QRS width duration was comparable in these groups. LVEF was associated independently with LVMD explaining $60 \%$ of its variation. A cut-off value of LVEF $\leq 55 \%$ was detected in LVMD with $100 \%$ specificity and $47 \%$ sensitivity.

The merits of the study are: (1) Showing that LVMD exists in about 50\% of patients with RBBB while QRS width was comparable in all these patients. (2) It seems that EF, rather than electrical parameters, is the main determinant of LVMD.

However, there are significant disadvantages: (1) A small group of RBBB patients was studied and therefore results should be confirmed in a larger group. (2) The results of LVMD better to be calculated from normal local database, thus, abnormal values will be considered as 2 Standard Deviation above normal values. (3) Regarding LVEF, it seems that the majority of the patients were in the normal range of $\geq 55 \%$ and only $11 \%$ were with LVEF $<40 \%$ which might be relevant for CRT. In spite of all these limitations, this article demonstrated that substantial number of patients with RBBB have LV mechanical dyssynchrony which is correlated with reduced LV function. This information might be useful when evaluating indications for cardiac resynchronization therapy. However, larger group of RBBB patients with and without LV dysfunction should be studied, in order to appreciate the usefulness of LVMD in selection of patients for CRT.

Of note, gated SPECT MPI and phase analysis is a useful comprehensive cardiac imaging that supplies an accurate and reproducible assessment of myocardial ischemia and scar as well as systolic, diastolic function and LVMD. All these variables have crucial value in assessing patients with heart failure with or without LBBB or RBBB for therapeutic decision including CRT.

\section{Disclosure}

The authors declare that they have no financial conflicts of interest.

\section{References}

1. Mirvis DM, Goldberger AL. Electrocardiography. In Braunwald's heart disease, a textbook of cardiovascular medicine, 10th edn. Philadelphia: Elsevier Saunders 2015;114-51

2. Hesse B, Diaz LA, Snader CE, Blackstone EH, Lauer MS. Complete bundle branch block as an independent predictor of all-cause mortality: Report of 7,073 patients referred for nuclear exercise testing. Am J Med 2001;110:253-9.

3. Bussink BE ${ }^{1}$, Holst AG, Jespersen L, Deckers JW, Jensen GB, Prescott E. Right bundle branch block: Prevalence, risk factors, and outcome in the general population: Results from the Copenhagen City Heart Study. Eur Heart J 2013;34:138-46

4. Takamatsu H, Tada H, Okaniwa H, Toide H, Maruyama H, Higuchi R, Kaseno K, Naito S, Kurabayashi M, Oshima S, Taniguchi K. Right bundle branch block and impaired left ventricular function as evidence of a left ventricular conduction delay. Circ J 2008;72:120-6.

5. Haghjoo M, Bagherzadeh A, Farahani MM, Haghighi ZO, SadrAmeli MA. Significance of QRS morphology in determining the prevalence of mechanical dyssynchrony in heart failure patients eligible for cardiac resynchronization: Particular focus on patients with right bundle branch block with and without coexistent leftsided conduction defects. Europace 2008;10:566-7.

6. Chandra R, Zolty R, Palma E. A left hemiblock improves cardiac resynchronization therapy outcomes in patients with a right bundle branch block. Clin Cardiol 2010;33:89-93.

7. Atwater BD, Wagner GS, Kisslo J, Risum N. The electromechanical substrate for response to cardiac resynchronization therapy in patients with right bundle branch block. Pacing Clin Electrophysiol 2017;40:1358-67.

8. Byrne MJ, Helm RH, Daya S, Osman NF, Halperin HR, Berger RD, Kass DA, Lardo AC. Diminished left ventricular dyssynchrony and impact of resynchronization in failing hearts with right versus left bundle branch block. J Am Coll Cardiol 2007;50:148490.

9. Sillanmaki S, Lipponen JA, Tarvainen MP, Laitinen T, Hedman $\mathrm{M}$, Hedman A, et al. Relationships between electrical and mechanical dyssynchrony in patients with left bundle branch block and healthy controls. J Nucl Cardiol 2018.

10. Uebleis C, Hoyer X, Van Kriekinge SD, Schuessler F, Laubender RP, Becker A, et al. Association between left ventricular mechanical dyssynchrony with myocardial perfusion and functional parameters in patients with left bundle branch block. J Nucl Cardiol 2013;20:253-61.

11. Hara H, Oyenuga OA, Tanaka H, Adelstein EC, Onishi $\mathrm{T}$, McNamara DM, Schwartzman D, Saba S, Gorcsan J 3rd. The relationship of QRS morphology and mechanical dyssynchrony to long-term outcome following cardiac resynchronization therapy. Eur Heart J 2012;33:2680-91.

12. Leong DP, Höke U, Delgado V, Auger D, Thijssen J, van Erven L, Bax JJ, Schalij MJ, Marsan NA. Predictors of long-term benefit of cardiac resynchronization therapy in patients with right bundle branch block. Eur Heart J 2012;33:1934-41.

13. Chen J, Garcia EV, Folks RD, et al. Onset of left ventricular mechanical contraction as determined by phase analysis of ECGgated myocardial perfusion SPECT imaging: Development of a diagnostic tool for assessment of cardiac mechanical dyssynchrony. J Nucl Cardiol 2005;12:687-95.

14. Henneman MM, Chen J, Ypenburg C, Dibbets P, Bleeker GB, Boersma E, et al. Phase analysis of gated myocardial perfusion single-photon emission computed tomography compared with tissue Doppler imaging for the assessment of left ventricular dyssynchrony. J Am Coll Cardiol 2007;49:1708-14. 
15. Lin X, Xu H, Zhao X, Folks RD, Garcia EV, Soman P, et al. Repeatability of left ventricular dyssynchrony and function parameters in serial gated myocardial perfusion SPECT studies. J Nucl Cardiol 2010;17:811-6.

16. Zafrir N, Nevzorov R, Bental T, Strasberg B, Gutstein A, Mats I, et al. Prognostic value of left ventricular dyssynchrony by myocardial perfusion gated SPECT in patients with normal and abnormal left ventricular functions. J Nucl Cardiol 2014;21:53240
17. Gimelli A, Liga R, Giorgetti A, Favilli B, Pasanisi EM, Marzullo P. Determinants of left ventricular mechanical dyssynchrony in patients submitted to myocardial perfusion imaging: A cardiac CZT study. J Nucl Cardiol 2016;23:728-36.

18. Sillanmaki S, Aapro S, Lipponen J, tarvainen $\mathrm{P}$, Laitinen $\mathrm{T}$, Hedman $M$ et al. Electrical and mechanical dyssynchrony in patients with Right Bundle Branch Block. J Nucl Cardiol 2018. In press 